\title{
Hubungan antara Work Life Balance dengan Employee Engagement Pada Bank Sinarmas KC Medan
}

\section{The Relationship between Work Life Balance with Employee Engagement at Bank Sinarmas Medan Branch}

\author{
Rebecca(1), Sarinah(2) $^{(2)}$ Achmad Irvan Dwi Putra ${ }^{(3)}$ \\ Fakultas Psikologi, Universitas Prima Indonesia, Indonesia \\ Diterima : 13 April 2020; Disetujui : 17 April 2020; Dipublish : 30 April 2020 \\ *Corresponding author: E-mail: Rebeccagoh19@gmail.com
}

\begin{abstract}
Abstrak
Tujuan dari penelitian ini adalah untuk mengetahui hubungan antara work life balance dengan keterikatan karyawan. Untuk penelitian ini yang menjadi subjek penelitian adalah karyawan pada PT Bank Sinarmas KC Medan, meliputi karyawan bagian Operasional maupun Non operasional yaitu sebanyak 111 orang karyawan dengan menerapkan teknik total sampling. Alat yang digunakan dalam metode pengumpulan data adalah dengan metode skala likert. Perhitungan dilaksanakan dengan menggunakan metode uji asumsi untuk mengetahui analisis korelasi dan regresi linear serta menentukan data yang telah dikumpulkan berdistribusi normal atau tidak. Untuk melakukan analisis data maka digunakan analisa Product Moment dengan menggunakan SPSS 21 for Windows. Diperoleh nilai $\mathrm{r}=0.493$, dan $\mathrm{p}=0.000(\mathrm{p}<0.05)$ dari hasil analisis yang mengindikasikan adanya hubungan positif antara work life balance dengan keterikatan karyawan. Disamping itu, hasil penelitian juga menunjukkan bahwa menurut $\left(\mathrm{R}^{2}\right)$ yang diberikan variabel work life balance dengan keterikatan pegawai adalah sebesar 24.3 persen, dan sementara 75.7 persen dipengaruhi oleh faktor-faktor lainnya yang tidak diuji dalam studi.

Kata Kunci: Employee Engagement; Kehidupan Pekerjaan.
\end{abstract}

\begin{abstract}
The purpose of the research is to determine the relationship between work life balance with employee engagement. This study uses workers at PT Bank Sinarmas Medan Branch, includes operasional and non operational employees, that is consisting of 111 people as subject of study who were selected by using total sampling technique. The tool used in the data collection method is the likert scale method. Data were obtained form a scale to measure work life balance and employee engagement.The calculation is done using assumption test method to find out the correlation analysis and linear refression and determine the data has been collected is normally distributed or not. Analysis of the data used was performed by Product Moment Analysis through SPSS 21 for Windows. The result of data analysis indicated that $r=0.493$ and $p$ $=0.000(p<0.05)$, it means that there was a positive relationship between work life balance and employee engagement. The results of this study indicated that the contribution $\left(R^{2}\right)$ given to the work life balance to employee engagement intention was $75.7 \%$, the remaining $44.6 \%$ were affected by other factors not examined in this study.
\end{abstract}

Keywords: Employee Engagement; Work Life Balance.

Rekomendasi mensitasi :

Rebecca., Sarinah., \&. Putra, A.I.D. (2020). Hubungan antara Work Life Balance dengan Employee Engagement Pada Bank Sinarmas KC Medan. Jurnal Penelitian Pendidikan, Psikologi dan Kesehatan (J-P3K), 1(1): 44-49. 


\section{PENDAHULUAN}

Dalam

menjalan

tentunya setiap manusia memiliki beberapa aspek dalam kehidupannya. Salah satu dari aspek tersebut adalah karier. Karier merupakan suatu perkembangan dan kemajuan dalam pekerjaan seseorang. Setiap pekerjaan memiliki hubungan erat antara pegawai dengan perusahaan. Hal ini memunculkan adanya keterlibatan karyawan.

Saat ini perusahaan berlombalomba untuk meningkatkan kualitas sumber daya manusia didalamnya. Berbagai macam usaha pun dilakukan, seperti pelatihan dalam bentuk training dan mengadakan ujian tertulis untuk pegawai secara berjangka. Selain itu, berbagai peraturan juga dibuat guna meningkatkan kedisiplinan. Berbagai fasilitas perusahaan disediakan demi menunjang motivasi dan prestasi pegawai, mulai dari tersedianya berbagai jenis mesin teknologi canggih untuk mendukung produktivitas pegawai hingga tunjangan, dan jaminan kesehatan bagi keluarga pegawai.

Meskipun perusahaan telah melakukan pengelolaan sumber daya manusia (SDM), masih ada sebagian besar pegawai yang merasa kurang terikat dengan pekerjaan. Karyawan yang terlibat akan benar-benar peduli dengan visi perusahaan dan mereka memiliki komitmen emosional terhadap perusahaan dan pekerjaan yang mereka miliki saat ini, yang berarti bahwa mereka akan bekerja atas nama tujuan organisasi dan bukan hanya untuk tanggal pembayaran atau promosi berikutnya. (Forbes, 2012).
Menurut Luthans (2006), saat individu bergabung dengan perusahaan, masing-masing individu membawa nilai dan kepercayaan yang berbeda baik itu dari dalam diri maupun dari perusahaan tempat bekerja. Tetapi, kadang nilai dan kepercayaan tersebut tidak cukup untuk membuat individu berhasil di dalam perusahaan. Individu harus memiliki pribadi yang baik dalam diri sehingga dapat membuat dirinya bertahan dalam suatu perusahaan.

Dari pendapat ahli diatas, maka dapat kita lihat bahwa setiap pekerjaan memiliki hubungan erat antara pegawai dengan perusahaan. Hal ini memunculkan adanya keterlibatan karyawan. Keterlibatan Karyawan adalah sebuah konsep dasar dalam upaya memahami dan menjelaskan, baik secara kualitatif maupun kuantitatif, sifat hubungan antara organisasi dan karyawannya (Breukelen,2004). Employee engagement adalah tingginya tingkat hubungan emosional dan intelektual yang diberikan individu kepada pekerjaan, organisasi, atasan, atau rekan kerja yang secara bergantian mempengaruhi individu dalam meningkatkan upaya kinerja (Marciano 2010).

Pada kenyataannya, banyak kasus yang membuktikan bahwa keterikatan pegawai ini masih belum dapat terlaksana secara nyata dalam lapangan pekerjaan. Sumber Daya Manusia akan ditempatkan oleh organisasi sebagai aset yang harus ditingkatkan efisiensi dan produktifitasnya secara konsisten. Dan oleh karena adanya konsep work life balance maka kebijakan pihak manajemen memberdayakan organisasi melalui jumlah waktu bekerja (working time) harus lebih efisien sehingga 
pagawai akan merasa lebih dihargai.

Tidak hanya keseimbangan waktu tetapi juga keseimbangan keterlibatan dan keseimbangan kepuasaan dalam bekerja. Beberapa aspek tersebut juga tentunya harus dapat menciptakan hubungan ramah keluarga di organisasi baik secara eksternal maupun internal. Keberhasilan dalam sebuah organisasi tentunya memiliki kebijakan kehidupan yang terstruktur dengan cara mengikuti dan mempraktekkan kebijakan yang ada. Selain hal tersebut dapat mendukung kualitas organisasi, hal ini juga dapat menjadi upaya dalam mempertahankan karyawan di organisasinya. Setiap organisasi yang mendorong kebijakan dan praktik keseimbangan kerja-hidup akan memiliki keterlibatan karyawan yang positif.

Agar kualitas serta komitmen dari para pekerja tetap terjadi maka setiap Organisasi yang memiliki keterlibatan langsung akan memberikan sejumlah peraturan yang dapat menguntungkan organisasi melalui komitmen dan dedikasi kepada karyawannya.

Hal yang tidak mudah bagi setiap individu adalah ketika mereka harus menginvesasikan diri mereka tidak hanya dalam peran kehidupan pribadi mereka, tetapi dalam organisasi secara keseluruhan. Salah satu contoh kebijakan nyata yang banyak ditawarkan oleh perusahaan saat ini adalah dengan menawarkan program family-friendly benefits yang dibutuhkan oleh karyawan guna untuk menyeimbangkan kehidupan dan pekerjaan, yang termasuk job sharing, flextime, telecommunicating dan lain sebagainya.
Keseimbangan antara kehidupan di dalam pekerjaan yang dapat meningkatkan semangat kerja yang tinggi dan juga memunculkan perasaan puas serta memiliki rasa tanggung jawab penuh baik didalam pekerjaan sekalipun hal ini merupakan sebuah tantangan yang tidak mudah untuk memanajemen berbagai tuntutan pekerjaan dan tanggung jawab untuk pekerjaan dan juga keluarga.

\section{METODE PENELITIAN}

Variabel-variabel yang digunakan dalam penelitian ini adalah Work life balance sebagai variable independent dan Employee engagement sebagai variabel dependent.

Berikut perincian jumlah subjek penelitian pada tabel dibawah ini. Teknik menentukan sampel adalah menggunakan teknik total sampling. Pengertian dari Total sampling yaitu menggunakan semua jumlah populasi untuk dijadikan sampel oleh karena itu sampel sama banyaknya dengan populasi penelitian (Sugiyono, 2007).

Menurut Sugiyono, total sampling merupakan teknik yang tepat untuk jumlah populasi yang mendekati 100. Potensi kesalahan pengukuran akan semakin rendah jika jumlah sampel yang digunakan tidak berbeda jauh atau sama dengan jumlah sampel.Maka dari itu, seluruh populasi dijadikan sampel penelitian semuanya.

Total sampling atau sampling jenuh adalah teknik sampling jika pengambilan sampel dari semua anggota populasi yang kecil, sehingga sampel dalam penelitian ini adalah seluruh karyawan operasional maupun non operasional di Bank Sinarmas KC Medan yang berjumlah 111 orang. 
Teknik analisis yang digunakan untuk menganalisis data hasil penelitian ini adalah teknik korelasi Product Moment dari Pearson yang merupakan alat uji statistik yang digunakan untuk menguji hipotesis dua variabel dengan menggunakan program SPSS 21 for windows. Alasan penggunaaan metode ini dalah agar dapat diketahui hubungan antara work life balance dengan employee engagement. Sebelum data-data yang terkumpul di analisa, terlebih dahulu dilakukan uji asumsi yang meliputi Uji normalitas digunakan untuk mengetahui apakah data terdistribusi dengan normal atau tidak.

\section{Korelasi Product Moment} mensyaratkan bahwa data harus terdistribusi dengan normal, dan dalam hal ini digunakan Kolmogorov Smirnov $Z$. Adapan kriteria yang digunakan adalah apabila $\mathrm{P}>0,05$ maka tidak berdistribusi normal (Azwar, 2010)

Uji linearitas untuk mengetahui apakah dua variable yang akan dikenai prosedur analisis statistic korelasional menunjukkan hubungan yang linear atau tidak. Jika $\mathrm{P}<0,05$ maka hubungan atara kedua variable yaitu work life balance dan employee engagement dikatakan linier dan sebaliknya jika $\mathrm{P}>0,05$ maka hubungan kedua variabel dikatakan tidak linier (Azwar, 2010).

\section{HASIL DAN PEMBAHASAN}

Hasil penelitian pada 111 karyawan PT Bank Sinarmas KC Medan yang digunakan sebagai subjek penelitian, mengungkapkan bahwa hubungan antara work life balance dan keterikatan pegawai dapat ditemukan dengan koefisien korelasi Product Moment sebesar $\mathrm{r}=0.493$ dan nilai $\mathrm{p}=0.000$, maksudnya work life balance yang semakin tinggi maka keterikatan pegawai akan mengikuti atau semakin tinggi pula, dan hal itu berlaku sebaliknya dimana work life balance yang semakin rendah maka rasa keterikatan pegawai pada pekerjaan juga semakin rendah.

Dari hasil penelitian dapat diketahui bahwa keberadaan hubungan antara work life balance dengan keterikatan pegawai. Penelitian yang dilakukan Aghaei dan Savari (2014) juga sama dengan hasil penelitian ini dimana secara jelas mengindikasikan bahwa antara keseimbangan kehidupan pribadi dan pekerjaan dengan keterikatan pegawai pada karyawan-karyawan mempunyai hubungan yang signifikan. Sementara itu koefisien determinasi $R$ Square $\left(\mathrm{R}^{2}\right)$ menunjukkan nilai 0.243 .

Menurut hasil yang diperoleh kesimpulanya yaitu, 24.3 persen work life balance mempengaruhi keterikatan pegawai pada karyawan di PT Bank Sinarmas tbk, sementara itu 75.7 persen dipengaruhi oleh faktor lainnya. Hal itu mengindikasikan bahwa rata-rata karyawan-karyawan PT Bank Sinarmas Tbk memiliki work life balance yang tinggi bisa diindikasikan oleh data penelitian terdapat 106 karyawan dengan presentase 95.5 persen masuk dalam kategori tinggi, kemudian 5 karyawan masuk dalam kategori memiliki work life balance sementara dengan presentase sebesar 4.5 persen menunjukkan bahwa work life balance karyawan tidak ada yang rendah.

Menurut uraian diatas maka kesimpulannya yaitu rata-rata karyawankaryawan PT Bank Sinarmas tbk memiliki work life balance yang tinggi.

Berdasarkan hasil observasi dan wawancara terhadap karyawan-karyawan 
PT Bank Sinarmas tbk menunjukkan work life balance yang tinggi dengan presentase 95.5 persen terlihat dari dimensi time management. Hasil wawancara dengan beberapa karyawan-karyawan PT Bank Sinarmas tbk menyatakan bahwa dengan memiliki kemampuan dalam membagi waktu antara kehidupan pribadi membuat keseimbangan dalam menjalankan pekerjaan lebih menyenangkan dan lebih teratur.

Diketahui juga bahwa skala employee engagement karyawan yang menjadi subjek penelitian menunjukkan rata-rata mean empirik yaitu 114.34 dengan standar deviasi 10.833 .

Berikut adalah perbandingan data empiris dan hipotetik employee engagement,

Tabel 1. Perbandingan Data Empirik dan Hipotetik Employee Engagement

\begin{tabular}{llll}
\hline Variabel & Empirik & Hipotetik & Ket \\
\hline Employee & 80 & 48 & Min \\
Engagement & 136 & 192 & Max \\
& 114.34 & 120 & Mean \\
\hline
\end{tabular}

Hasil analisis untuk skala employee engagement menunjukkan nilai mean empiric > mean hipotetik yaitu $109.58>$ 90, maka kesimpulan yang bisa dibuat yaitu employee engagement pada umumnya menunjukkan tingkat yang lebih tinggi pada subjek dibandingkan populasinya.

Tabel 2. Kategorisasi data Employee Engagement

\begin{tabular}{llll}
\hline Skala & Rentang & Kategori & Persen \\
& Nilai & & \\
\hline Employee & $\mathrm{x}<72$ & 48 & Min \\
Engagement & $72 \leq 114$ & 192 & Max \\
& $\mathrm{x} \geq 114$ & 120 & Mean \\
\hline
\end{tabular}

Menurut kategori pada tabel 2 maka bisa diketahui bahwa tidak ada subjek (0 persen) yang mempunyai keterikatan pegawai rendah, kemudian ada 34 subjek (30.6\%) yang mempunyai keterikatan pegawai sedang, dan diketahui 77 subjek (69.4\%) yang memiliki keterikatan pegawai tinggi. Maka berdasarkan penjelasan diatas kesimpulan yang bisa dibuat yaitu subjek penelitian rata-rata mempunyai rasa keterikatan pada pekerjaan yang cukup tinggi.

\section{KESIMPULAN}

Berdasarkan penelitian yang sudah dilaksanakan maka peneliti bisa menyimpulkan bahwa terdapat hubungan yang positif dan signifikan antara work life balance dengan keterikatan pegawai, artinya karyawan yang bisa membagi kehidupan pribadi dan pekerjaan memiliki keterikatan pegawai yang tinggi juga. Sementara itu , beberapa faktor lain yang juga dapat mempengaruhi keterikatan pegawai diantaranya seperti work values, self-efficacy, locus of control, attitude toward teaching, labor relationship, job satisfaction, dan teaching competency.

\section{DAFTAR PUSTAKA}

Aveli, Arikunto, S. (2010). Prosedur Penelitian. Jakarta: PT Rineka Cipta.

S. 2017. Employee Engagement and Effects of Work Life Balance in Software Industries in Chennai. International Journal of Pure and Applied Mathematics. . Vol. 116, No.22. Diakses tanggal 20 November (2018) dari: http://www.ijpam.eu

lbrecht, S. L. (2008). Handbook of employee engagement. UK : Edward Elgar Publishing Limited

Amstrong Michael, Armstrong's Handbook of Human Resource Management Practice.London: Kogan Page, (2009)

Albrecht, S. L. (2008). Handbook of employee engagement. UK : Edward Elgar Publishing Limited.

Bakker, B. A., \& Leiter, P. M. (2010). Work Engagement A Handbook of Essential Theory and Research. Psychology Press.

Iqbal Iqra.,dkk. (2017).Impact of Employee Engagement on Work Life Balance with the moderating Role of Employee Cynicism. International Journal of Academy Research in Business and Social 
Sciences.Vol.7,No.6. Diakses tanggal 23 November 2018 dari https://www.hrmars.com/journal

Lockett Katherine, (2008). Work/Life Balance for Dummies - Achieve Greater job Satisfaction, Bussienss and Wellbeing Through balancing Your Work and Life. Indianapolis: Wiley Publisihing,

Marciano, P. D. (2010). Carrots and Sticks Don't Work:Build a Culture of Employee Engagement with the Principles of RESPECT. New York: McGraw-Hill. 